\title{
KNOWLEDGE AND SELF CARE PRACTICE OF HEART FAILURE PATIENTS IN BIRATNAGAR
}

\author{
Saraswati Basnet \\ Lecturer TUIOM, \\ Biratnagar Nursing Campus, Morang, Nepal
}

\author{
Dr Deepak Sigdel, \\ HOD, Medicine Koshi Zonal Hospital \\ Morang, Nepal
}

\begin{abstract}
Tthis study entitled "Knowledge and Self-Care Practice of Heart Failure Patients in Biratnagar". The aim of the study was to identify knowledge and self care practice of heart failure patient. The study was conducted at Koshi Zonal Hospital in Biratnagar. Non probability purposive sampling technique was used. The total sample size was 109. An interview schedule consisting semi-structured interview schedule was used. The data was analyzed by using both descriptive and inferential statistics. The finding of this study revealed that around sixty-eight percent of respondents were age 61 to 80 years. Most of the (62.4\%) respondents were female. Most the (35.8\%) respondents were Bramin /Chhetri among ethnicity. More than half $(51.4 \%)$ respondents were illiterate. Most of the $(70.6 \%)$ of respondents were having poor knowledge whereas only twenty nine percent of respondents having good knowledge about self care management of heart failure. Most of the (64.2\%) of respondents were having poor practice whereas only thirty three $(33 \%)$ percent of respondents having good practice about self-care management of heart failure. It is also concluded that relation between level of knowledge significantly association with level of practice (P-value, 0.003 and 0.000 ) in which having good knowledge had good practice and having poor knowledge having poor practice of self-care management of heart failure patient.
\end{abstract}

Keywords- Knowledge, Self-care Practice, Heart failure, Health information, occupation.

\section{INTRODUCTION}

Over the last decade, heart failure (HF) has become a growing epidemic. Currently, HF impacts over 5.7 million people in the United States; more than 15 million people in Europe; approximately 500,000 people in Canada; and 277,800 people in Australia. Despite evidence-based therapies in $\mathrm{HF}$, the prevalence, incidence, and mortality have progressively increased over the past 25 years. The projected HF prevalence in 2030 is expected to further increase by $25 \%$ (Casimir, Williams, Liang, Pitakmongkolkul, \& Slyer, 2013).

Heart failure is identified as a leading cause of hospitalizations, morbidity, mortality, and rising healthcare costs for nearly six million Americans. Self-care is a decisionmaking process, where patients perform activities to prevent symptoms (maintenance) and respond to symptoms as they occur (management). Self-care maintenance activities for heart failure patients include exercising daily, eating a low sodium diet, monitoring fluid intake, and monitoring weight. Patients may respond to symptoms by engaging in the following selfcare management activities: consulting their healthcare provider, reducing fluid and sodium intake, and increasing the dose of a diuretic. However, patients' adherence to recommended self-care behaviors varies greatly and is generally poor (Chen, et al., 2013).

A study conducted in the United States, Europe, Australasia and South America, among 5964 heart failure patients studies result found that most patients reported taking their medications as prescribed but exercise and weight monitoring were low. In 14 of the 22 samples, more than $50 \%$ of the patients reported low exercise levels. In 16 samples, less than half of the patients weighed themselves regularly, with large differences among the countries. Self-care with regard to receiving an annual flu shot and following a low sodium diet varied most across the countries (Ben, et al., $2013 \mathrm{Jul}$ ).

The study of the 113 patients surveyed, two thirds of the patients reported receiving information or advice about self-care from health care providers. When asked how much they knew about congestive heart failure, however, $37 \%$ said "a little or nothing," 49\% said "some," and only 14\% said "a lot." Approximately $40 \%$ of the patients did not recognize the importance of weighing themselves daily and $27 \%$ weighed themselves twice a month or less often. Although $80 \%$ of the patients knew they should limit their salt intake, only one third always avoided salty foods. Additionally, 25\% of the patients did not appreciate the risk of alcohol use and $36 \%$ believed they should drink a lot of fluids (Hanyu,Deidre, Burgress, Wise, Crispell, \& Hershberger, 1999).

The multiple linear regression analysis indicated that a higher knowledge score was associated with being married, prior hospitalization, and having received both advice and information about self-care from physicians or nurses. A poor adherence behavior score was associated with being unmarried, lower perceived self-efficacy, a lack of knowledge about self-care, and no prior hospitalization (Hanyu, Deidre, Burgress, Wise, Crispell, \& Hershberger, 1999) 


\section{International Journal of Engineering Applied Sciences and Technology, 2019 \\ Vol. 4, Issue 5, ISSN No. 2455-2143, Pages 133-137 \\ Published Online September 2019 in IJEAST (http://www.ijeast.com)}

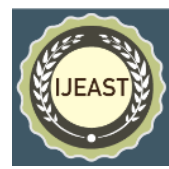

\section{RESEARCH MethodOLOGY}

Descriptive research design was used to conduct this study. The study was carried out in Koshi Zonal Hospital, Biratnagar. Koshi Zonal Hospital is a public hospital and famous for poor \& medium class peoples. It is a 350 bedded Governmental Hospital provides the services to the people, of the Eastern Region of Nepal. Non Probability purposive sampling technique was used to select appropriate sample. All heart failure patients attending in study area having following criteria was included in the study. Forty (40) years and above, Diagnosed heart failure prior to 6 months or more, having stable health condition, able and willing to give information, subjects who can speak and understand Nepali Language. Data collection period was used 12 weeks, from Poush $15^{\text {th }}$ to Chaitra $30^{\text {th }} 2073$. The estimated sample size was 109 diagnose heart failure patients. A modified Semistructured interview schedule as per the objectives of the study was developed the based on QUERI-CHF Follow-Up Phone Interview Questions for self care practice measurement. But the measurement of self care knowledge was developed with the help of Extensive literature review, consultation with colleagues, other expert and researcher's knowledge and experience. This instrument was developed both English and Nepal version too. Content validity of the instrument was established by consultation with peers, other experts and physician expert. Pretesting of the instrument was conducted with $10 \%$ of sample in golden Hospital in Biratnagar where attending Out Patient Department for follow up investigation and treatment of the patient with heart failure. Instrument was modified, if required, as per the outcome of the pretest. Instrument consisted of 3 parts: Part I- socio-demographic information, Part II- items related to knowledge on self care, Part III- items related to practice on self care. The knowledge was classified as, poor and good according to 100 scoring of the knowledge component of heart failure. Practice was classified as also 100 scoring of patient done daily practice related question of heart failure adherent treatment. Level of knowledge and practice was categories according to based on median (50\%) as above median good knowledge and practice below median poor knowledge and practice. Research proposal was approved from the concern authority Koshi Zonal Hospital. A written permission was obtained from authority as Koshi Zonal Hospital from where data was collected. Verbal informed consent was obtained from the subjects prior to data collection. Confidentiality was ensured throughout the data collection period and throughout study period. The collected data was edited, coded, classified and analyzed by using descriptive and inferential statistics.

\section{Results Discussion AND DATA ANALYSiS}

\subsection{Socio-Demographic Variable of Heart failure Patient}

The study result reveals that around sixty-eight percent of respondents were age 61to 80 years. Most of the $(62.4 \%)$ respondents were female. Most the $(35.8 \%)$ respondents were Bramin /Chhetri among ethnicity. More than half $(51.4 \%)$ respondents were illiterate. most of the $(51.4 \%)$ respondents engaged in house work.

3.2 Knowledge on Exercise, weight monitoring, worsening signs, fluid intake and salt intake of Heart Failure

The study result reveals that most of the $(56 \%)$ respondents knew on do light exercise. more than half $(60.6 \%)$ respondents were known about weight monitoring. Most of the $(61.5 \%)$ respondents were known fluid intake more than 4 glass. more than half $(67.6 \%)$ of respondents recognized more than 5 worsening signs of H.F. most of $(69.7 \%)$ of respondents mean of low salt diet cause no fluid retention.

3.3 Self Care Practice on taking low salt diet, symptoms recognize, Ankle Swelling, taking medication and forget medication of Heart Failure Patients

The study result reveals that most of the $(55 \%)$ respondent's practice no taking low salt diet. More than half $(59 \%)$ respondent recognized symptoms of H.F. Half of the $(50.4 \%)$ respondents use their medication regularly. More than half (57.8\%) respondents no checked their ankle swelling. More than half $(51.5 \%)$ of the respondents no avoiding sick.

3.4 Self Care Practice on Weight Monitoring, weight increase, Identify high salt diet, follow up visit and Physical Activity

The study result reveals that most of the $(85.3 \%)$ respondents not do routine weight monitoring. more than half $(56 \%)$ of respondents not visited their physician when increased the weight. more than half (57.8) of respondent not identified the high salt diet. half of the $(50.5 \%)$ respondents did follow up visit. less than half (45\%) of respondents were not done physical activity.

\subsection{Level of Knowledge on self care of Heart Failure} patient

The study result shows that most of the (70.6\%) of respondents were having poor knowledge about self care management of heart failure whereas only twenty nine percent of respondents having god knowledge about the self-care management of heart failure.

\subsection{Level of Self- Care Practice of Heart Failure patient}

The study result shows that most of the (64.2\%) of respondents were having poor practice about self-care management of heart failure self care whereas only thirty three percent of respondents having good practice about self-care management of heart failure self-care. 


\section{International Journal of Engineering Applied Sciences and Technology, 2019 \\ Vol. 4, Issue 5, ISSN No. 2455-2143, Pages 133-137 \\ Published Online September 2019 in IJEAST (http://www.ijeast.com)}

Table 7

Relation between level of Knowledge and Level of Practice of Heart Failure Patients

\begin{tabular}{|c|c|c|c|}
\hline \multicolumn{4}{|c|}{$n=109$} \\
\hline \multirow[t]{2}{*}{ Characteristics } & & & \\
\hline & $\operatorname{good}$ & poor & \\
\hline Level & 32 & 77 & \\
\hline Knowledge & & & 0.000 \\
\hline $\begin{array}{l}\text { Level } \\
\text { practice }\end{array}$ & 39 & 70 & \\
\hline
\end{tabular}

Table 7 depicts, that relation between level of knowledge significantly association with level of practice in which having good knowledge had good practice and having poor knowledge having poor practice about self-care management of heart failure.

\section{DISCUSSION}

This section deals with the comparison between the finding from literature review and findings from this research. It mainly focuses on what are similarities and dissimilarities and what may be possible causes of those similarities and dissimilarities of literature review and from this research.

Present study finding reveals that more than half $(52.3 \%)$ of respondents were up to 5 years. Most of the $(50.5 \%)$ respondents were received information from health personnel. More than half $(58.9 \%)$ respondents were no experienced about dangerous signs and symptoms. Most of (38.9\%) respondents were heard term heart failure very little whereas study conducted by (Driscoll, Davidson, Clark, \& Zoe, 2009) contracdict finding reveals that a low sodium diet, engaging in physical activity, restricting their fluid and adhering to a complex medication regimen. Patients who can effectively self-manage their symptoms through lifestyle modification and adhere to complex medication regimens will experience fewer hospitalizations and improved quality of life.

Present study finding reveals that most of the $(55 \%)$ respondent's practice no taking low salt diet. More than half (59\%) respondent recognized symptoms of H.F. Half of the $(50.4 \%)$ respondents use their medication regularly. More than half $(57.8 \%)$ respondents no checked their ankle swelling. More than half $(51.5 \%)$ of the respondents no avoiding sick. similar study conducted by (Ben, et al., $2013 \mathrm{Jul}$ ) in the United States, Europe, Australasia and South America, among 5964 heart failure patients on studies contradict result found that most patients reported taking their medications as prescribed but exercise and weight monitoring were low. In 14 of the 22 samples, more than $50 \%$ of the patients reported low exercise levels.
Present study among 109 respondents, finding reveals that shows that most of the $(70.6 \%)$ of respondents were having poor knowledge about self care management of heart failure whereas only twenty nine percent of respondents having good knowledge about the self-care management of heart failure whereas similar study conducted by (Boyoung, Moster, \& Kethlen, July, 2014) in Europe among 612 patients with heart failure research result revealed that $45 \%$ of patient with high knowledge and poor self care other are low knowledge and $32 \%$ in group with low knowledge and poor self care may be the similar setting or same pattern of socio-demographic variable.

Present study finding reveals that shows that most of the $(70.6 \%)$ of respondents were having poor knowledge about self care management of heart failure whereas only twenty nine percent of respondents having good knowledge about the self-care management of heart failure whereas similar study conducted by (Baidya, Aryal, \& Krettek, 2013) at Jhaukhel, Duwakot Health Demographic surveillance in two urbanizing village near Kathmandu among 777 respondents result shows that nearly $44 \%$ of respondents had insufficient knowledge of heart failure and only $14.7 \%$ had high satisfactory attitude may be the similar setting or socio-demographic pattern of respondents.

Among 109 respondents, study result shows that most of the $(64.2 \%)$ of respondents were having poor practice about selfcare management of heart failure self care whereas only thirty three percent of respondents having good practice about selfcare management of heart failure self-care whereas similar study conducted by (Baidya, Aryal, \& Krettek, 2013) at Jhaukhel, Duwakot Health Demographic surveillance in two urbanizing village near Kathmandu among 777 respondents contradictory result shows that $19.5 \%$ had satisfactory and $13.5 \%$ had highly satisfactory practice may be the differences in respondent characteristics, socio-demographic factors.

Among 109 respondents, present study result depicts, that relation between levels of knowledge significantly association with level of practice in which having good knowledge had good practice and having poor knowledge had poor practice about self-care management of heart failure. Similar study was conducted by (Boyoung, Moster, \& Kethlen, July, 2014) in Europe among 612 patients with heart failure research contradict result revealed that forty-five percent of patients in the group with high knowledge and poor self-care had a PHQ9 score of 10 or higher, compared with $29 \%$ in the group with low knowledge and good self-care, $32 \%$ in the group with low knowledge and poor self-care, and $22 \%$ in the group with high knowledge and good self-care. Another study conducted by (Yahya, Muhamad, \& Yusoff, 2012) in Kelantan, Malaysia among 448 women attended primary care facilities, study result supported that there were significant association between attitude and knowledge, practice and knowledge and practice and attitude which were found to be strong $(0.10$, $0.20),(0.10,0.18)$ and $(0.26,0.40) 95 \%$ CI, respectively. 


\section{International Journal of Engineering Applied Sciences and Technology, 2019 \\ Vol. 4, Issue 5, ISSN No. 2455-2143, Pages 133-137 \\ Published Online September 2019 in IJEAST (http://www.ijeast.com)}

\section{CONCLUSION}

Based on finding it is concluded that most of respondents were having poor knowledge and practice about self care management of heart failure whereas only one fourth of respondents having good knowledge and practice about self care management of heart failure. there were relation between level of knowledge significantly association with level of practice in which having good knowledge had good practice and having poor knowledge having poor practice of self-care management of heart failure patient.

\section{ACKNOWLEDGEMENT}

I would like to express my sincere gratitude to the Medical Superintendent, Koshi-Zonal Hospital for constant inspiration, academic support, valuable suggestion and providing platform for research work. I would my sincere gratitude to this research, co-author Deepak Sigdel HoD Medicine, for Invaluable expert suggestion and found management. I am very grateful to Biratnagar Nursing campus, Koshi Zonal Hospital and all the respondents for their valuable information and cooperation.

\section{REFERENCES}

1.Hanyu, N., Deidre, N., Burgress, D., Wise, K., Crispell, K., \& Hershberger, R. E. (1999). Factors Influencing Knowledge of and Adherece to selfCare Among Patients With Heart Failure. Arch Intenal Med :159(14) :1613-1619.

2.Zamanzadeh, V., Valizadeh, L., Fatemeh, J., Hossein, N., \& Ahdieh, M. (2012). Self-Care Behaviors among Patients with Heart Failure in Iran. Journal of Caring Sciences 1(4), 209-214.

3. Macabasco, O., Connell, A., Dewalt, D., Broucksou, K., Hawk, V., Baker, D., et al. (2011). Realtionship between literacy, knowledge, self- care behaviours, and heart failure- related quality of life among patients with heart failure. J Gen Intern Med, 979-86.

4. Chen, A. M., Yehle, K. S., Albert, N. M., Ferraro, K. A., Masson, H. L., Murawaki, M. M., et al. (2013). Health Literacy Influence Heart Failure Knowledge Attainment but Not Self-Efficacy for Self- Care Over Time. Nursing Research and practice Volume, 8. 127-30.

5. Casimir, Y. E., Williams, M. M., Liang, M. Y., Pitakmongkolkul, S., \& Slyer, J. T. (2013). Effectiveness of patient-centerd self- care education foradults with heart failure on knowledge,self-care behaviour, and readmision. The JBI Database of Systematic Reviews and Implementation Reports ISSN 2202_4433 , 920-28.
6. Greal, a. H., Hogan, M. J., Irwn, C. W., Maggio, N. J., \& Jurgens, C. J. (23 July, 2014). Heart failure self-care interventions to reduce clinical events and symptom burden. Research Report in Clinical Cardiology, 243-257.

7. Santos, D. A., Santos, M. A., Santos, B. D., Lopes, D. d., \& Cruz, M. (2015). Self CAre in Heart Failure Patients. Revista Latina- Americana Enfermagem online version 1518-8345 ,Vol.23,no.4, 104.

8. Connell, A. M.-O., Dewalt, D. A., Broucksou, K. A., Hawk, V., Barker, D. N., Schillinger, D., et al. (2011). Relation between Literacy, Knowledge, Self- CareBehaviours, and Heart Failure Patients_ related Quality of life Among Patients with Heart Failure. Journal of Gen Interm Med26(9), , 979-86.

9. Boyoung, H., Moster, D. K., \& Kethlen, D. ( July, 2014). Knowlledge is insufficient for self-care among heart failure patients with psychological distress. Journal of Health Psychology Vol.33(7),588-596.

10. Boyne, O. J., Vrijhoef, H. J., Spreeuweenberg, M., Weerd, G. D., Kragten, J., \& Goegels, P. A. (2014). Effect of tailored telemonitoring on heart failure patients' knowledge, self care, self efficacy and adherence:A randomized controlled trial. European Journal of Cardiovascular Nurse , 243252.Vol.13,3:pp.

11. Shrestha, U. K., Alurkar, V. M., Baniya, R., Barakoti, B., Poudel, D., \& Ghimire, S. (7, March, 2015). Profiles of heart failure in the western region of Nepal: prognostic implications of the MELD-XI score. Internal Medicine Inside ISSN 2052-6954, 54-60 .

12. Baskota, M., Rao, B. S., \& Shakya, R. (2006). Study on the prescribing Patients of Drugs Used in Heart Failure . KATHMANDU UNIVERSITY JOURNAL OF SCIENCE, ENGINEERING AND TECHNOLOGY Vol. 2,(1) 1-3.

13. BIBLIOGRAPHY $\backslash 1033$ Baidya, A., Aryal, U. R., \& Krettek, A. (2013). Cardiovascular health knowledge, attitude and practice/behaviour in an urbanising community of Nepal: a populationbased cross-sectional study from JhaukhelDuwakot Health Demographic Surveillance Site. BMJ open Access Vol. 3(10) .

14. BIBLIOGRAPHY V 1033 Oli, N., Vaidhya, A., Subedi, M., \& Krettek, A. (2014). Experiences and perceptions about cause and prevention of cardiovascular disease among people with cardiometabolic conditions: findings of in-depth interviews from a peri-urban Nepalese community. Journal of Global Health Action eISSN 1654-9880 , 56-78. Vol, 7. 
International Journal of Engineering Applied Sciences and Technology, 2019

Vol. 4, Issue 5, ISSN No. 2455-2143, Pages 133-137

Published Online September 2019 in IJEAST (http://www.ijeast.com)

15. Yahya, ,. R., Muhamad, o., \& Yusoff, H. M. (2012). Association between Knowledge, Attitude and Practic. International Journal of Collaborative Research on , 1507-1724.

16. Driscoll, A., BIBLIOGRAPHY VI 1033 Davidson, P., Clark, R., \& Zoe, N. H. (22, 2009). tailoring consumer resources to enhance self-care in chronic heart failur . Australian Critical Care, p. 133-140. 